\title{
The future design of electricity markets: capacity payments or smart solutions?
}

\author{
R. Haas \\ Energy Economics Group, Vienna University of Technology, Austria
}

\begin{abstract}
Currently, increasing shares of intermittent renewable energy sources (RES) are changing the common pattern of electricity markets, especially in Western Europe. This development has led to the call for capacity markets in addition to the current energy-only markets. The objective of this paper is to discuss the relevance and the effects of capacity markets and the alternatives. The most important conclusion is that the evolution of a flexible system for the renewable integration of RES, considering other elements such as grid extension, smart grids, technical demand-side management, economic demand response and short and long-term storage, is favorable to the capacity markets in Western Europe and may also serve as a role model for largely RES-based electricity suppliers in other countries world-wide.
\end{abstract}

Keywords: electricity markets, intermittent renewables, capacity payments.

\section{Introduction}

In recent years electricity generation from "new" renewable energy sources (RES) excluding hydro has been growing from less than 1\% in 1997 to about 9\% in 2010 (Fig. 1). Especially the increasing shares of intermittent RES from wind and photovoltaics (PV) in Germany have changed the usual pattern of electricity markets in Western Europe. The fact that these must run capacities are offered at zero costs over a large time per year has led to the argumentation that fossil plants like combined-cycled gas turbines or coal power stations become economically less attractive because of lower full load hours per year. This argument has led to the call for "capacity" markets in addition to the current "energy-only" markets. The idea is that specific owners of a flexible power plant should be paid for holding the plant ready for operation. 


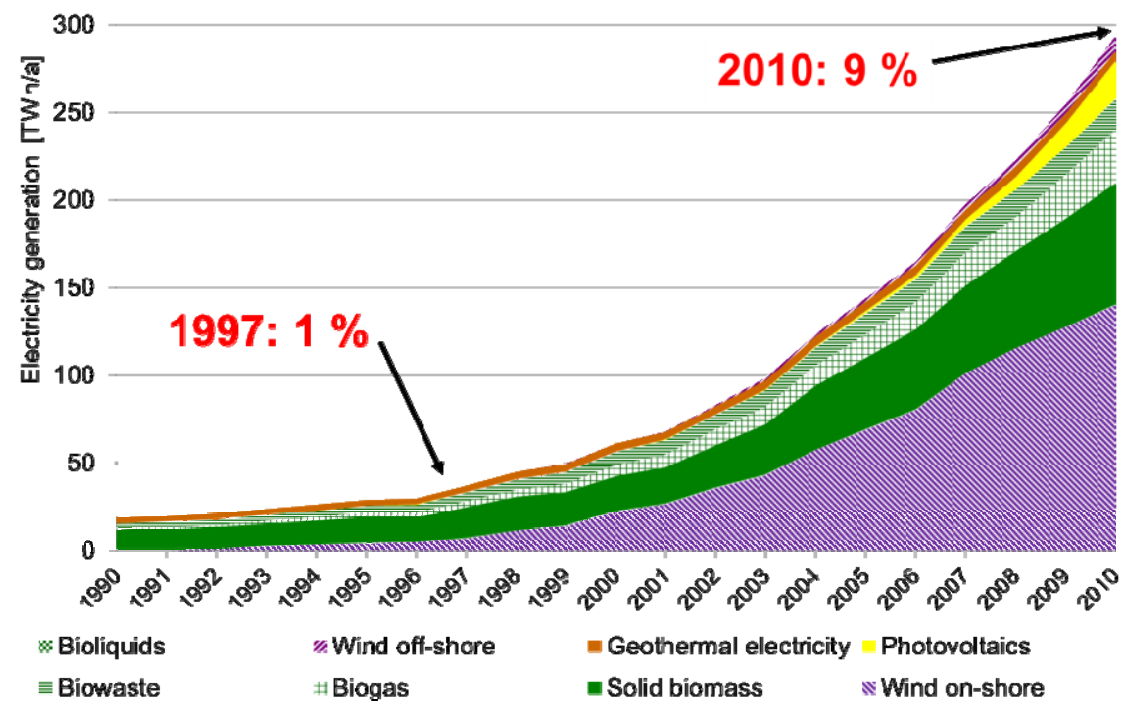

Figure 1: Development of electricity from "new" renewables (excluding hydro) in EU-27 between 1990-2010, in TWh [4].

The idea of capacity payments for power plants is not new. It already existed in the initial English pool in the early 1990s as well as in Sweden, Finland and some states of the USA in recent years, e.g. Inagendo [1]. Currently, also the European Commission is looking for a proper new or revised electricity market design for the future [2]. In this context it is of interest that different countries put different emphasis on this wording. While in some countries like France the emphasis is on DESIGN (which means central planning) other countries try to focus on the word MARKET by means of competition. The core objective of this paper is to discuss the relevance and the effects of such a system and the alternatives. It builds on basics described in Haas et al. [3].

In the literature some analyses on capacity markets $(\mathrm{CM})$ are already from the 1990s. In recent years the number of contributions has increased tremendously. Yet, surprisingly only few papers question the need for $\mathrm{CM}$ in principle. The majority of papers focus on the design of CM, e.g. [5]. An exemption is Erdmann [6] who argues in favour of decentralized solutions.

\section{How prices come about}

This section discusses how the liberalization of the electricity markets in Europe changed the formation of prices in wholesale markets, and - as further described in Section 3 - the impact of rising shares of renewables on spot market electricity prices.

The liberalization process in Europe started in the late 1980s in the UK and gradually migrated to continental Europe with the 1999 the EU-directive [7]. One of the major features of the liberalized electricity markets was that the 
pricing regimes changed. In former regulated markets, prices were established by setting a regulated tariff, which was calculated by dividing the total costs of supplying service by the number of kWhs sold - with some differences between different groups of customers - see Fig. 3. The major change that took place after the liberalization was that prices were now expected to reflect the marginal costs of electricity generation (e.g., Stoft [8]). At the time when liberalization started considerable excess capacities existed in Europe. This led to the expectation that prices will (always) reflect the short-term marginal costs (STMC) as illustrated in Fig. 2. The major reason for this expectation was that there were huge depreciated excess capacities at the beginning of liberalisation. As shown in Fig. 2, the intersection of the supply curve with demand determines the market clearing price at the system marginal costs. The curve $\mathrm{D}_{\mathrm{t} 1}$ shows the demand curve at times of low demand e.g., at night and $\mathrm{p}_{\mathrm{t} 1}$ is the resulting (low) electricity price. $\mathrm{D}_{\mathrm{t} 2}$ shows high demand times, e.g., at noon, and $\mathrm{p}_{\mathrm{t} 2}$ is the resulting (high) electricity price. The difference between $\mathrm{p}_{\mathrm{t} 2}$ and $\mathrm{p}_{\mathrm{t} 1}$ is the socalled price spread further described below. It provides useful information, for example, on the economic attractiveness of storage, which will be of high relevance in markets with large share of renewables. Until recently, the price spread has been of interest mainly with respect to pumped storage. That is to say, during periods when prices are low, water can be pumped into reservoirs; while generating electricity when the opposite is true.

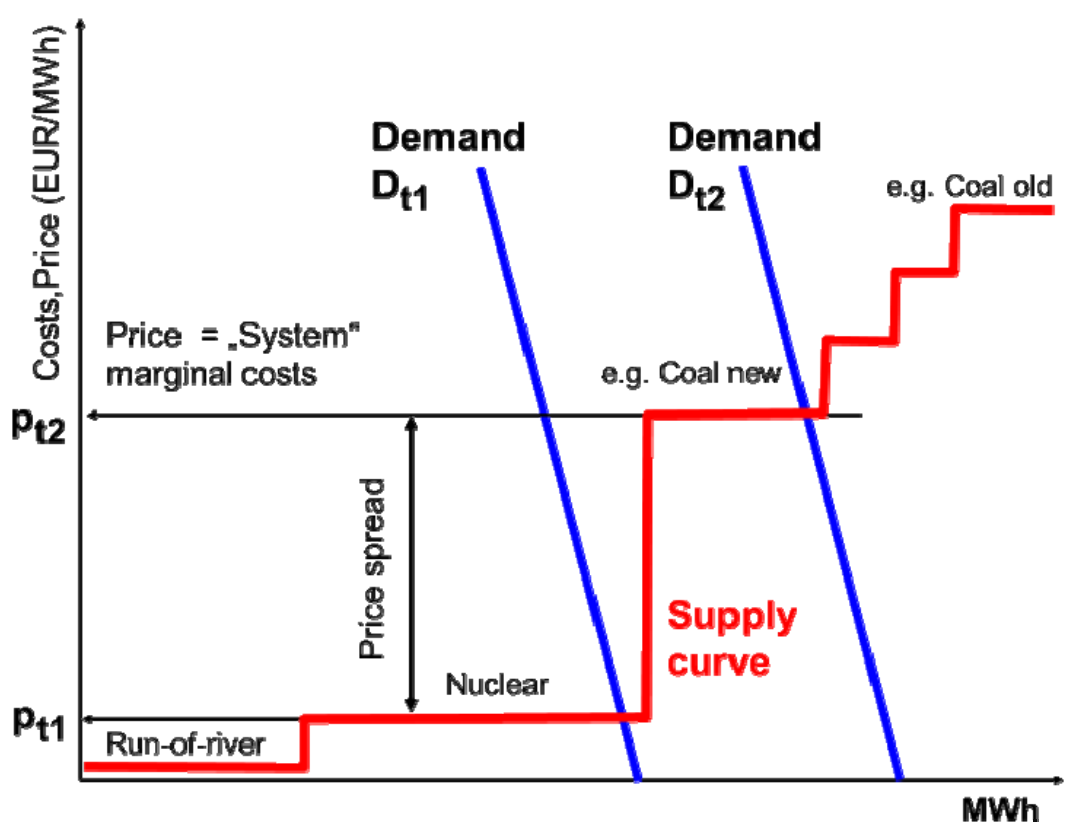

Figure 2: How prices come about in markets with conventional capacities. 
The STMC price regime, illustrated in Fig. 2, of course, will not be permanent nor always apply. Once excess generation capacity is exhausted, there will be a shift towards long-term marginal costs (LTMC). Similarly, generators are likely to behave strategically during high demand periods in markets with limited peaking capacity. Moving forward, one can expect deviations from the STMC price regime, as illustrated in Fig. 3. Moreover, as described below, the introduction of large amounts of renewables with zero or negative marginal cost will further affect the principles behind STMC.

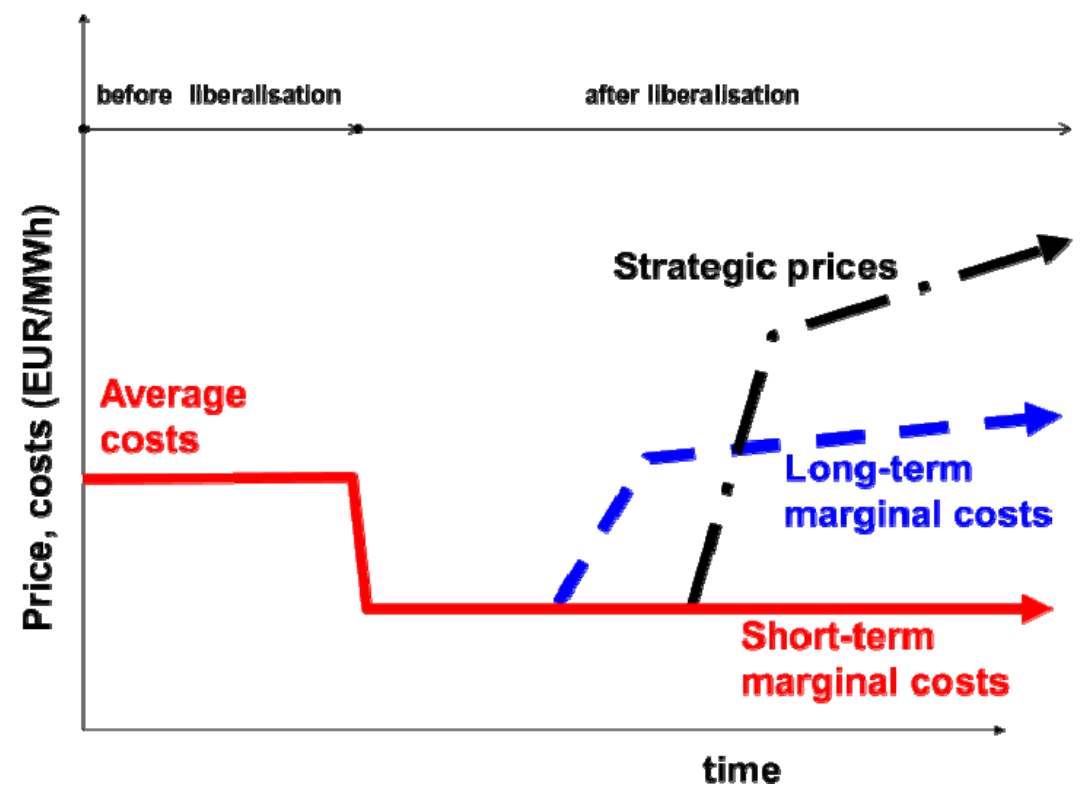

Figure 3: Changes of pricing electricity before and after liberalization of electricity markets.

\section{How intermittent renewables impact prices in electricity markets}

The rise of intermittent renewables will impact spot prices, trading patterns and dispatching of conventional generation The explanation is simple. On a sunny day with ample solar generation, the supply curve is shifted to the right as schematically shown in Fig. 4, which essentially pushes nuclear and fossil fueled generation "out of the market".

Aside from the above-described effects, intermittent renewables will also influence the costs at which fossil generation - especially natural gas - are offered. The reason is that they could lead to much lower full load hours, e.g. only 1000 instead of $6000 \mathrm{~h} / \mathrm{yr}$ before. Yet, the revenues earned from these hours must cover both the fixed and variable costs, see also Haas et al. [3]. 


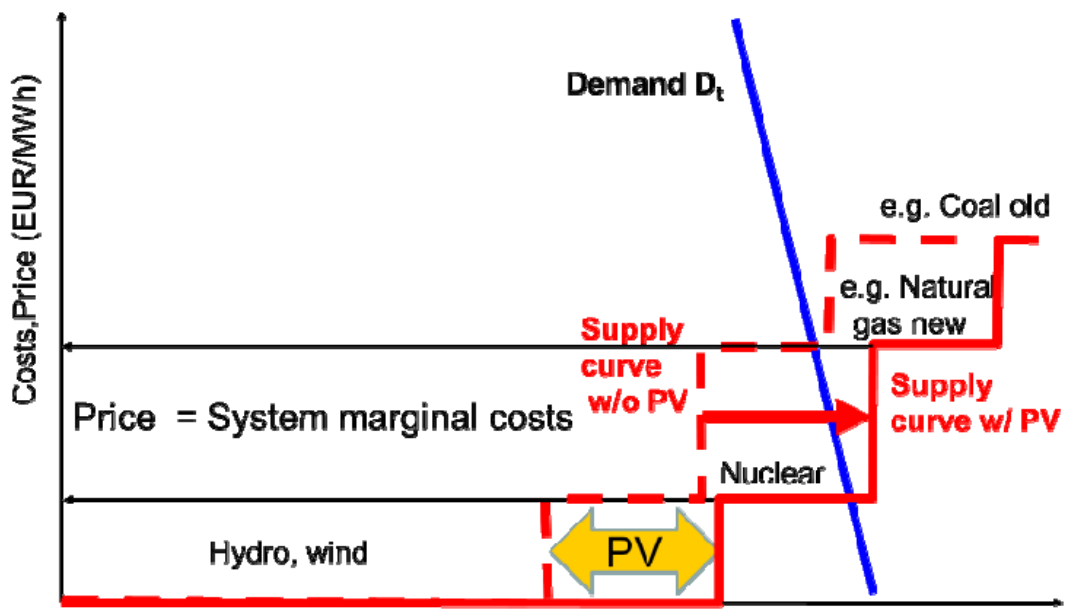

MW

Figure 4: Merit order supply curve with and without additional PV capacities at on-peak time on a bright summer day with short term marginal costs for conventional capacities.

This leads to the following categories of presumed "problems":

1. Prices decrease to Zero or are even negative at a number of days;

2. Lacking contribution margin to fixed costs for conventional flexible power plants.

However, what is still open in this discussion is that it is not yet clear, on how many days very high and on how many days very low (or negative) prices will prevail and how high or how low these prices will be.

Of further relevance in this context is how the price spread in European markets will evolve in the future as larger amounts of PV, solar thermal and wind generation are added to the network. The consequence for electricity prices are shown in Fig. 5 where a hypothetical scenario with high levels of generation from wind, PV and run-of-river hydro plants over a week in summer are depicted using synthetic hourly data for an average year in Germany. The graph shows significant volatilities in electricity market prices with total costs charged for conventional capacities - black solid line - ranging from zero to 14 cents $/ \mathrm{kWh}$ (these 14 cents/ $\mathrm{kWh}$ result from full load hours of about $1,000 \mathrm{~h} / \mathrm{yr}$ ) within very short-term time intervals. The longer-term impact of intermittent renewables on price spread on the grid is subject to speculation. The intuitive explanation is that when renewables are plentiful, say during windy or sunny periods, the prices will be extremely low, approaching zero or possibly going negative, while at other times - when demand is high and renewables are scarce - prices can be much higher due to strategic bidding by fossil generators exercising market power. This is graphically shown in Fig. 5 - black solid line. 


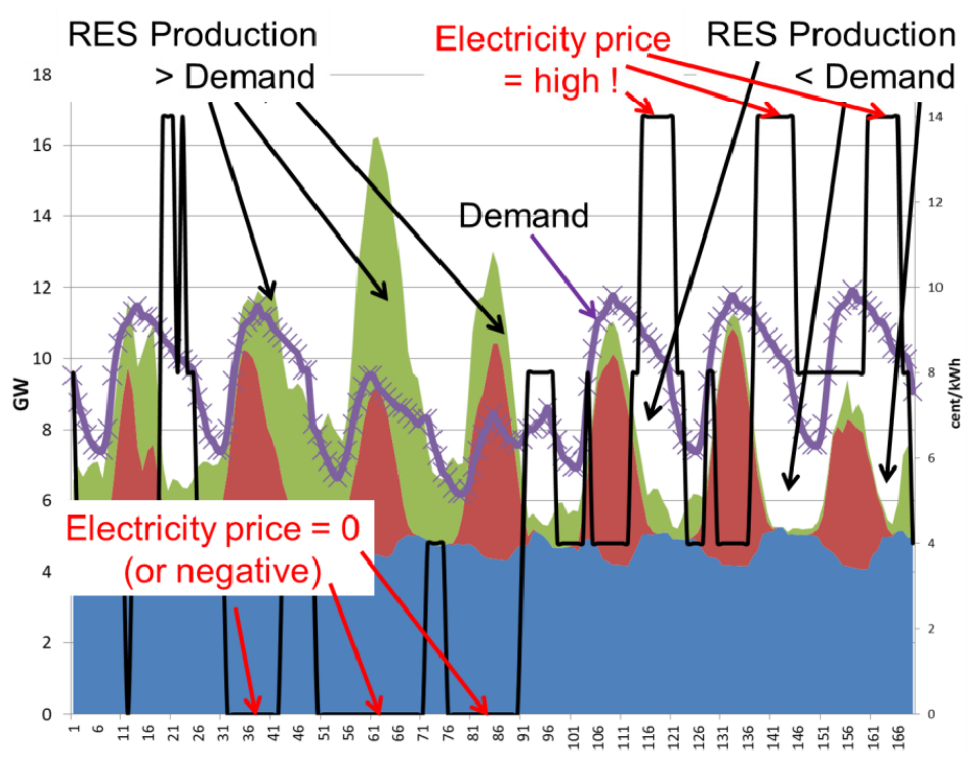

Figure 5: Development of electricity from wind, PV and run-of-river hydro plants over a week in summer on an hourly base in comparison to demand and corresponding prices.

A major finding from this figure is that in the long run large amounts of intermittent RES will lead to increasing new price spreads. It is important to note that future high prices will not necessarily appear at peak-demand times but at times of low renewables availability. This will also change the operation of pumped hydro facilities and lead to new investment in energy storage technologies to take advantage of significant price differentials. Over time, the familiar patterns of the night-to-day-shift of generation will change in response to the unpredictable and variable rhythm of renewable generation. The most likely consequence of increased price volatility will be to make storage and flexible peaking units much more valuable than they currently are.

Given the price pattern in Fig. 5 we are convinced that it would be attractive for (some but sufficient) power plant operators to stay in the market or even to construct a very efficient new plant. This would lead to the market model of a revised energy-only market.

\section{Supply security vs. market design}

One major reason for the call for centralized capacity payments (CCP) is to retain supply security in the electricity system. The historical (anachronistic) definition of supply security is: at every point-of-time every demand has to be met regardless of the costs. Fig. 6 depicts this principle graphically. In this context it is important to note that supply security is an energy economic term. It is different from technical system reliability. 


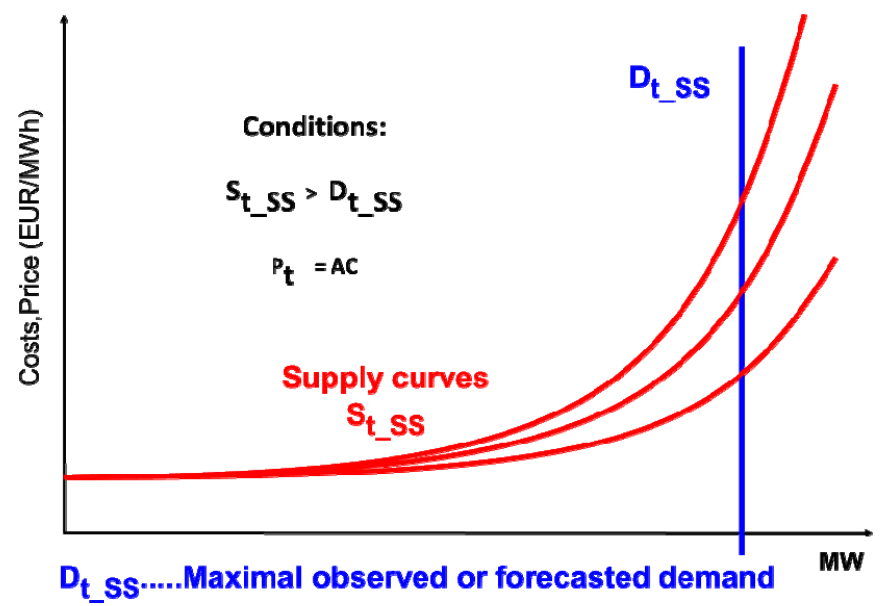

Figure 6: $\quad$ Historical (anachronistic) definition of supply security.

The core problem is that so far the demand-side has been fully neglected with respect to contributing to an equilibrium of demand and supply in an electricity market. No culture of integration of demand has so far been developed. The major reason for this is that in times of regulated monopolies every demand could be met due to significant excess capacities and in the liberalized markets still excess capacities remained. This aspect - to develop the impact of demandside and customers WTP - is essential for a real electricity market and it is actually regardless of the aspect of an integration of larger shares of RES. In the context of the discussion of market design this historical view of supply security plus CCP) would lead to a new market DESIGN in the sense of a centrally planned economy.

On contrary to this central planning approach a market-based one would take into account customers WTP. The equilibrium between demand and supply would come about at lower capacities. It is also important to note that where WTP is lowest the MC of providing capacity are highest, see Fig. 7.

A market-based approach will further-on consider all options on the supplyside and the demand-side. There are much more dimensions than just generation for bringing about an equilibrium in electricity supply. The most important ones are, see Fig. 8:

- $\quad$ Demand-side management (technical): Measures conducted by utilities like cycling, control of demand, e.g. of cooling systems);

- $\quad$ Demand response due to price signals: Response of mainly large customers to price changes;

- Transmission grid extention: if the grid is extended there is in principle always more capacity available in the system and the volatility of RES a well as demand evens out;

- $\quad$ Smart grids: They allow variations in frequency (upwards and downwards regulation) and switch of voltage levels and contribute in this context to a load balancing; 
- $\quad$ Storages: short-term and long-term storages - batteries, hydro storages, or chemical storages like hydrogen or methane - can help to balance significant volatilities of RES generation.

The economic condition is that the marginal costs of all options must be equal: $\mathrm{MC}_{\mathrm{Gen}}=\mathrm{MC}_{\text {Sto }}=\mathrm{MC}_{\mathrm{Grid}}=\mathrm{MC}_{\mathrm{DSM}}$ and price equals $\mathrm{MC}$ and customers WTP: $\mathrm{P}_{\mathrm{t}}=\mathrm{MC}=\mathrm{WTP}$.

Note, that all load shift and storage measures will depend on the price spreads.

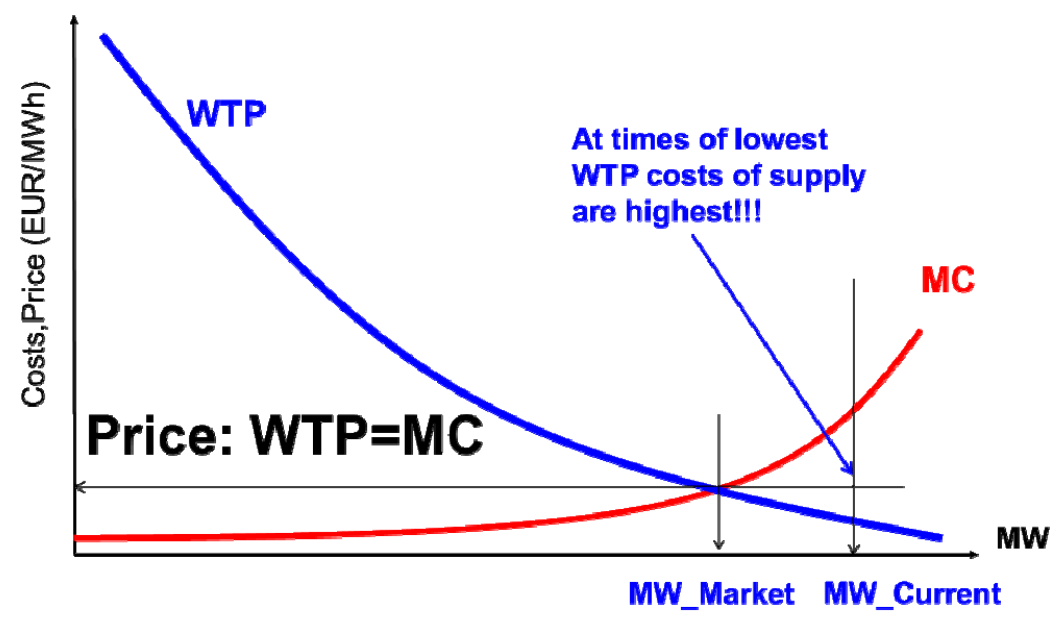

Figure 7: $\quad$ A market-based approach to supply security.

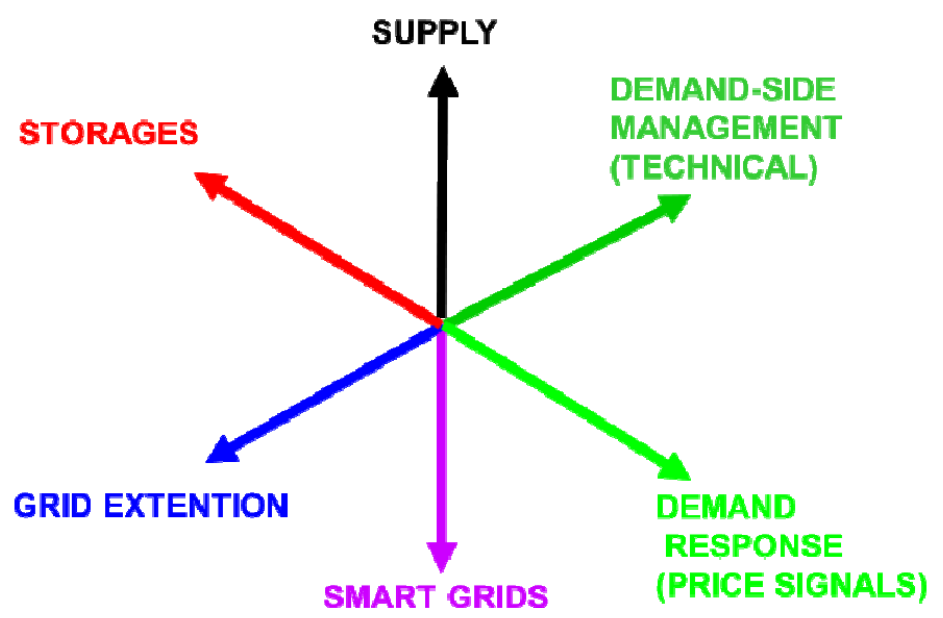

Figure 8: Dimensions of electricity markets. 


\section{New "market" models under discussion}

If we talk about capacity "market" models it is important to bear in mind that in most models it is virtually impossible to have finally a competitive "market". How should competition take place in a specific region with only one supplier? E.g. In Southern Germany or in France? In this context the following statement of the EWI Cologne, in favour of capacity "markets", is of great interest: "in the comprehensive as well as in the focused CM there are no market mechanisms" [10].

The major discussed market models are summarized in Table 1; see also the survey provided by Inagendo [1]. The classic energy-only market (EOM) focuses on $\mathrm{P}=\mathrm{STMC}$. The revised EOM-model described in Chapter 4 allows temporarily price increases above the STMC level. Including demand-side contracts leads to the EOM + DSC model. In this category the idea of Erdmann [9]) also fits, who suggests that the balancing groups should be responsible for providing capacities.

Finally two CCP models are discussed: One Comprehensive CCP model which treats existing and new capacities jointly [10] and a Focused CCP approach which differs between existing and new capacities. In both of these market models - as in the classic EOM the price should equal the STMC [10]).

Table 1: Survey on currently discussed electricity market models.

\begin{tabular}{|l|c|c|c|c|c|c|}
\hline & $\begin{array}{c}\mathrm{P}= \\
\text { STMC }\end{array}$ & $\begin{array}{c}\mathrm{P}= \\
\text { LTMC }\end{array}$ & $\begin{array}{c}\text { Demand- } \\
\text { side } \\
\text { contracts }\end{array}$ & $\begin{array}{c}\text { Existing } \\
\text { power } \\
\text { capacity }\end{array}$ & $\begin{array}{c}\text { New } \\
\text { power } \\
\text { capacity }\end{array}$ & $\begin{array}{c}\text { Government } \\
\text { owns power } \\
\text { plant }\end{array}$ \\
\hline EOM classic & $\mathrm{X}$ & & & & & \\
\hline EOM revised & $\mathrm{X}$ & $\mathrm{X}$ & $\mathrm{X}$ & & & \\
\hline EOM + DCM & $\mathrm{X}$ & & & & & \\
\hline $\begin{array}{l}\text { Comprehensive } \\
\text { CCP }\end{array}$ & $\mathrm{X}$ & & & $\mathrm{X}$ & $\mathrm{X}$ & \\
\hline Focused CCP & & & & & & \\
\hline $\begin{array}{l}\text { Strategic } \\
\text { reserve }\end{array}$ & $\mathrm{X}$ & & & & & \\
\hline
\end{tabular}

EOM...Energy-only market

CCP... Centralized capacity payments

DCM...Demand-side capacity market 
The major open questions regarding $\mathrm{CCP}$ are:

- Which quantity of capacity should get payments and where?

- How to split in existing and new capacity?

- How to tune with grid extention? Every grid extention has undoubtedly an impact of necessary capacities in a specific area

- Who plans? On national or international level? E.g. CCP in Germany influence operation of Austrian and Swiss hydro storage

Based on these open questions one of the most important aspects is the international dimension. The price patterns in different European electricity markets are shown in Fig. 9 for the period from 2000-2012 where to some extent price volatility and considerable differences between various sub-markets are observed. A remarkable convergence of prices has taken place even in Western continental Europe. Currently, there is a wide-integrated Western-Central European electricity market which consists (at least) of Germany, France, The Netherlands, Austria, Switzerland, Poland, Czech Republic. That is to say that any measure in one of these countries will affect the market structure in others.

The discussion in Europe starts with the request for CM on national level. Yet, because the Western European electricity markets is strongly integrated, the national planning activities has at least to some extent to consider the international dimension. Transboundary grid extentions and storage availability are some important aspects. This leads after some time undoubtedly to international planning of CM. The next logical step is to think about an international joint concept for financing. And this would lead very soon to central European planning.

The alternative would be strictly national CCP. Would they be more efficient? In this context the following statement of the EWI Cologne, in favour of CCP, is highly of interest: "If we introduce capacity markets they must really ensure full supply security. That is to say the capacities we need must at least to some extent be higher than expected demand, including a security margin" and further "in the comprehensive as well as in the focused CM there are no market mechanisms" [10]). Now imagine the excess capacity that comes about if all European countries do this on a national level.

The major reason for why, at least currently, there is no need for $\mathrm{CCP}$ in Europe is that there are still many other options in the market, which we think are by far not yet exhausted. However, to exhaust these options some dogmas have to be changed. Especially the historically prevailing and still existing definition of supply security - that every demand has to be met at every point-of-time regardless of what are the costs - has to be revised in a way that compares the costs of (all) supply-side and demand-side options as well as customers WTP for capacity depending on time.

In this context, of core relevance is finally that a demand-side capacity market is developed. So far consumers have never been asked what the value of capacity is for them and what they are willing to pay for specific quantities of capacity. A first analysis in this context has been conducted by Praktiknjo [11]). He clearly 
identifies two findings: (i) there is a quite different WTP between different groups of customers; (ii) it is very unlikely that generating electricity is always cheaper than saving capacity.

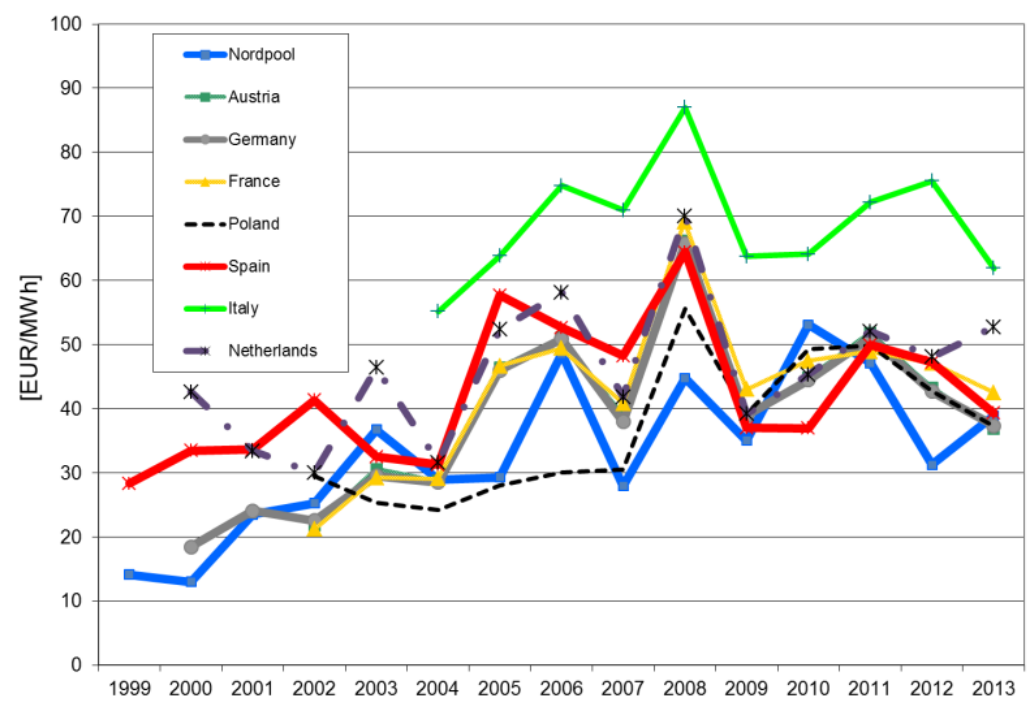

Figure 9: Development of spot market prices in different European electricity markets 2000-2013 (2013 preliminary).

\section{Conclusions}

The major conclusion of our analysis is that capacity markets are a step back to a planned economy with - all in all - much higher costs for society. The only "negative" aspect of a market without capacity component will be that - at least in the short run - temporarily higher costs than the short-term marginal costs will occur. However, after some time the market will learn to benefit from these higher costs and also from the very low costs at times when RES are abundant. A reasonable price spread will come about that provides incentives for different market participants. Moreover, in addition to pure power generation capacities other elements like Smart grids, technical and economic demand-side management, short-term storage options will even out a large part of the residual load profile (the difference between demand and supply from RES). The most important - so far neglected - issue for a real electricity market is the development of the demand-side.

Another conclusion is that the evolution of a creative system of integration of RES in Western Europe may serve as a role model for largely RES-based electricity supply systems in other countries world-wide. So there is especially now no need for CCP. If all our arguments would turn out to be wrong it would still be sufficient to introduce such a model and to abolish the electricity markets. 


\section{References}

[1] Inagendo: Funktionsweise und Nebenwirkungen von Kapazitätsmechanismen, 2013, Niederkassel.

[2] Koch Oliver, Electricity market design, Presentation at IAEE-conference, 18-21 July 2013, Düsseldorf.

[3] Haas R., Lettner G., Auer J., Duic N. "The looming revolution: How Photovoltaics will change electricity markets in Europe fundamentally", Energy 57, 2013, 38-53.

[4] EU: Energy pocket book, Luxemburg 2012.

[5] Cramton P., Ockenfels A.: Economics and Design of Capacity markets for the power Sector, Zeitschrift für Energiewirtschaft, 36, 2/2012, 113-134.

[6] Erdmann G., Kapazitätsmechanismus für konventionelle und intermittierende Elektrizität. In: Agora: "Brauchen wir einen Kapazitätsmarkt?" August 2012. 2012a.

[7] EC: Directive 96/92EC of the European Parliament and of the Council Concerning the Common Rules for the Internal Electricity Market. Official Journal L27 of 1/30/1997, Luxemburg. 1997.

[8] Stoft, St.: Power System Economics, IEEE Press, Piscataway, 2002.

[9] Erdmann G.: Das Entwicklungsverfahren des Marktes nutzen, Energie \& Management, 15.8.2012, 6. 2012b.

[10] Energie \& Management, 15.7.2013, 10-11.

[11] Praktiknjo, A.: Sicherheit der Elektrizitätsversorgung im Spannungsfeld der energiepolitischen Ziele Wirtschaftlichkeit und Umweltverträglichkeit, $\mathrm{PhD}$ thesis, Berlin, 2013. 